to work at first upon dissimilar objects and adjust the macular reception rate until a point is reached where marked neglect or long period alternation is replaced by rapid and equal periodicity. Attention is then given to the stereoscopic sections of the pictures. It will be found that having attacked unbalanced alternation, a situation is arrived at in which depth may now be appreciated. This achievement adds weight to the contention that alternation is essential for complete and accurate spatial orientation. Much work remains to be done with regard to the more detailed analysis of alternation in the optimum balance required to produce the greatest depth effect. It must be known what influences the master eye brings into the picture as a stabilising factor and centre of reference; and, what effects has the angle of separation of the line of vision of such an eye from the sagittal line.

To this end it is intended to carry these investigations through a large series of cases and in each instance to examine :-visual acuity with refraction; muscle balance including master eye and its relative ascendency over the other eye; depth perception as recorded by the rotating depth perception apparatus; and, the state of binocuiar reception and stereoscopic appreciation as studied with rotating stereogram.

\title{
ON DISABLEMENT AND SOCIAL CONDITIONS OF PATIENTS WITH PAST SYPHILITIC INTERSTITIAL KERATITIS*
}

BY

\author{
Esther DalsgaARD-Nielsen, M.D.
}

COPENHAGEN

I HAVE examined material comprising 173 patients with past interstitial keratitis. Of these patients 124 answered a call for re-examination while 49 were encountered accidentally in the course of this work. As to the gathering of this material I beg to refer to my book: "Keratitis parenchymatosa luica og dens Fœlgetilstande."1

The average age of these 173 patients was 32 years, with an average observation period of 20 years, the longest observation period covering 56 years. In the present paper I shall try to give an account of my findings concerning the disablement and social conditions of these patients.

\footnotetext{
* From the Departments of Ophthalmology of the Rigshospital (University Clinic) and the Kommunehospital (City Hospital), Copenhagen.
} 
In estimating the degree of disablement, I have based my judgment, for one thing, on the statements made by the patients themselves, as these data generally will illustrate the practical means of subsistence of the patients and hence afford a rather essential foundation for an appraisal of the fate of these patients.

Through these investigations, however, it turned out that the actual earning capacity of the patient did not always correspond with my findings on examination. Thus, for instance, some patients were able to get along remarkably well in spite of a very considerable decrease in their power of vision. In estimating their disablement, therefore, I have also made use of the calculation on which the public disablement insurance here in Denmark is founded. ${ }^{2}$ In this way I have arrived at a uniform estimation of the material, especially with regard to the mild degrees of disablement that do not assert their presence in any particular decrease in the practical earning capacity of the patients.

As to the social condition of the patients I have tried to obtain information about any family history of syphilis in the parents and in the brothers and sisters, the number of sisters and brothers, whether the patients have been married and have had any children, and how the health of these children has been. Finally, through comparison between the living conditions of these patients and of their parents I have tried to elucidate whether the disease has lowered the individual patient socially. This information has quite naturally, for the sake of discretion, often been very difficult and sometimes impossible to obtain. In this connection, it may be stated here that among the total number of patients covered by this re-examination-173 altogether- 96 (i.e. 55 per cent.) knew that they were suffering from congenital syphilis, while 45 (i.e. 26 per cent.) apparently knew nothing about their illness, and in 32 cases (i.e. 18 per cent.) it could not be ascertained whether the patients knew anything about the nature of their illness.

In speaking of the disablement of patients with syphilitic interstitial keratitis, we have also to reckon with the disability due to the acute eruption of the disease itself. As the acute eruption in most cases occurs at school-age, this disability will chiefly involve absence from school. With a view to this point, Carvill and Derby ${ }^{3}$ have reported that in a material of 200 cases 54 patients had to miss school for a period from 1 month to 3 years, whilst 31 had been able to attend school without any particular inconvenience. In 96 patients this morbid condition went on to permanent disablement.

We have to reckon it as a socially favourable fact that the keratitis usually manifests itself at such an early age that the patient has not yet commenced any occupational training, so that it will yet be possible to decide his future occupation according 
to his present strength of vision. There are, however, a good many cases in which the keratitis does not appear until the patient has entered into a certain occupation, and if this work requires a greater strength of vision than is left by the keratitis, the patient will have to look around for some other occupation, as a rule with smaller income.

How often this happens in practice, Igersheimer ${ }^{4}$ has tried to elucidate by questioning a fairly large number of patients with past interstitial keratitis. It was found that owing to the decrease in their power of vision several of these patients had been forced to adopt some simpler, less exacting, trades; but in these occupations they were fully able to compete with their normal fellow workers.

In my investigation, as already mentioned, I have paid particular attention to the question whether the disease has caused such a degree of disablement that it has impaired the practical earning capacity of the patient. In my material it was found that 79 per cent. of the patients stated themselves that they were perfectly capable of work, while 7 per cent. were only partially able to work, and 14 per cent. were disabled probably to a degree less than onethird of normal working capacity. As far as the statements made by the patients are concerned, one has to admit that these patients on the whole are getting along fairly well, even though the 14 per cent. with severe invalidity must be considered a considerable social encumbrance.

In the main, the statements made by the patients have agreed very well with the physician's estimation in the appraisal of the disablement. Only 3 patients, in their own opinion, gave a reduction in earning capacity that was considerably greater than could be demonstrated objectively. On the other hand, 2 patients testified to a very good working capacity in the trades they had selected, even though their disablement on physical examination was rather considerable; one was completely deaf, the other was a blind organ player.

In my material the symptoms causing disablement have been : impairment of vision, deafness, and nervous complications. In the aforementioned calculation of disablement I found that 51 per cent. of the patients showed a disablement of 0 per cent.; 55 per cent. of the patients showed a disablement of 5-20 per cent.; 9 per cent. of the patients showed a disablement of 25-60 per cent.; and 16 per cent. of the patients showed a disablement of $65-100$ per cent. By far the most frequent cause of disablement was impairment of vision, as this complaint appeared in 92 per cent. of the cases-and it was the only complaint in 72 per cent.whereas deafness was the cause of disablement in 27 per cent., and nervous complications in 3 per cent. 
Past Syphilitic Interstitial Keratitis

TABLE I

\begin{tabular}{|c|c|c|c|c|c|}
\hline I & \multicolumn{2}{|c|}{ II } & \multicolumn{2}{|c|}{ III } & IV \\
\hline $\begin{array}{c}\text { Ponset agec of } \\
\text { deafness }\end{array}$ & entire & material & number & of deaf & $\%$ \\
\hline $\begin{array}{r}1 \\
2 \\
3 \\
4 \\
5 \\
6 \\
7 \\
8 \\
9 \\
10\end{array}$ & $\begin{array}{l}173 \\
173 \\
1773 \\
173 \\
173 \\
173 \\
173 \\
173 \\
172 \\
172\end{array}$ & 173 & $\left.\begin{array}{l}0 \\
0 \\
0 \\
0 \\
0 \\
0 \\
2 \\
2 \\
1\end{array}\right\}$ & 5 & $2.9 \%$ \\
\hline $\begin{array}{l}11 \\
12 \\
13 \\
14 \\
15 \\
16 \\
17 \\
18 \\
19 \\
20\end{array}$ & $\begin{array}{l}172 \\
172 \\
171 \\
118 \\
165 \\
164 \\
160 \\
158 \\
154 \\
148\end{array}$ & 163 & $\begin{array}{l}0 \\
0 \\
0 \\
3 \\
1 \\
1 \\
1 \\
1 \\
1 \\
2\end{array}$ & 10 & $6,1 \%$ \\
\hline $\begin{array}{l}21 \\
22 \\
23 \\
24 \\
25 \\
26 \\
27 \\
28 \\
29 \\
30\end{array}$ & $\begin{array}{l}144 \\
139 \\
132 \\
125 \\
120 \\
109 \\
102 \\
96 \\
89 \\
86 \\
\end{array}$ & 114 & $\begin{array}{l}0 \\
1 \\
0 \\
0 \\
0 \\
0 \\
2 \\
0 \\
0 \\
0 \\
\end{array}$ & 3 & $2,6 \%$ \\
\hline $\begin{array}{l}31 \\
32 \\
33 \\
34 \\
35 \\
36 \\
37 \\
38 \\
39 \\
40\end{array}$ & $\begin{array}{l}84 \\
79 \\
75 \\
63 \\
57 \\
52 \\
47 \\
44 \\
42 \\
41\end{array}$ & 38 & $\left.\begin{array}{l}2 \\
0 \\
0 \\
0 \\
0 \\
0 \\
0 \\
1 \\
0 \\
1\end{array}\right)$ & 4 & $6.9 \%$ \\
\hline $\begin{array}{l}41 \\
42 \\
43 \\
41 \\
45 \\
46 \\
47 \\
48 \\
49 \\
50\end{array}$ & $\begin{array}{l}40 \\
35 \\
32 \\
29 \\
27 \\
26 \\
24 \\
23 \\
20 \\
20\end{array}$ & 28 & $\begin{array}{l}0 \\
0 \\
1 \\
0 \\
0 \\
0 \\
0 \\
1 \\
0 \\
0\end{array}$ & 2 & $7,1 \%$ \\
\hline $\begin{array}{l}\$ 1 \\
52 \\
53 \\
54 \\
35 \\
36 \\
57 \\
38 \\
99 \\
60\end{array}$ & $\begin{array}{l}20 \\
17 \\
15 \\
12 \\
11 \\
10 \\
9 \\
8 \\
7 \\
3\end{array}$ & 11 & $\begin{array}{l}1 \\
1 \\
0 \\
0 \\
0 \\
0 \\
1 \\
0 \\
0 \\
0\end{array}$ & 3 & $27.3 \%$ \\
\hline
\end{tabular}


Among the pathological changes in the eye that I found to be the cause of impairment of vision, corneal opacity was the most frequent, while refraction anomalies and choroiditis were considerably less frequent; and cataract and bulbar phthisis were even more infrequent.

With the exception of bulbar phthisis, which always is associated with a considerable decrease of vision, all the other morbid conditions mentioned above occasioned more or less severe impairment of vision.

After this there can be no doubt that impairment of vision is the most frequent cause of disablement. Here, however, we have to keep in mind the degrees of disablement involved. As to deafness, it is the general rule that this affection always implies a severe degree of disablement (50 per cent., after the scale here mentioned), even though experiences show that the practical earning capacity is not always lowered correspondingly.

As to the ear complications, I found, in my material, several interesting conditions that have been mentioned more fully in a

Fig. 1

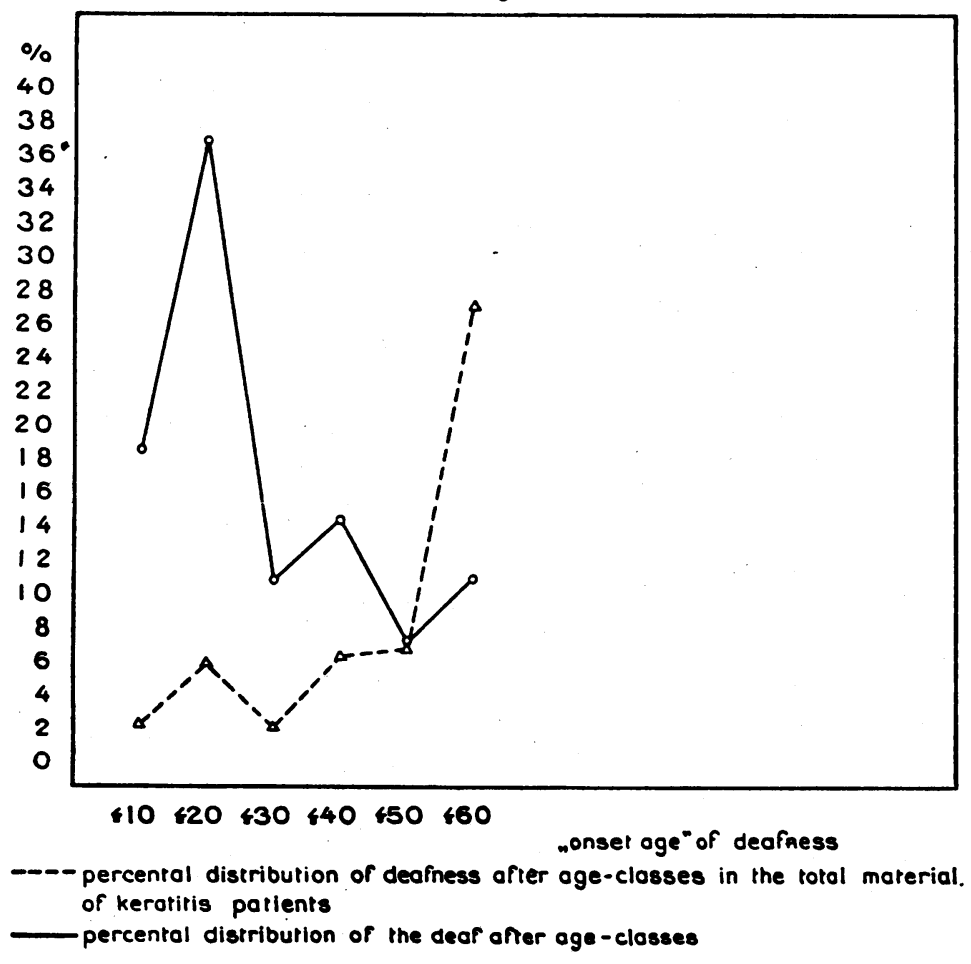


previous paper ${ }^{5}$ on the correlation between syphilitic interstitial keratitis and deafness. Here I shall merely give a brief summary of the more important results. The material was particularly suitable for an inquiry into the relation between ear complications and eye lesions, as none of the patients was summoned on account of his or her ear lesion. Ear complications were present in altogether 15.6 per cent. of these patients. A tabulation of these patients according to the age at which the deafness appeared, shows that the most frequent " onset age " is the decade of 10-20 years-what is quite in keeping with the findings reported by previous investigators. See Table I.

For further elucidation of the percentage distribution of deafness in this material, the findings are plotted graphically in Fig. 1 (dotted line) and for comparison, another curve (solid line) is plotted for the percentage distribution of the total number of deaf after age-classes.

From Table I and Fig. 1 (dotted line), an interesting fact is evident that has not been noticed previously, which was not at all evident from the immediate percentage distribution of the deaf (solid line), namely : that by far the greatest percentage of these patients become deaf as late as at the age of 50-60 years.

In order to illustrate how often we can expect to find patients with a past history of congenital syphilitic keratitis to become deaf in the different age-classes - that is, the percentage of deafness and its variation with increasing age-I have tabulated the material as shown in Table II.

In Table II the first column represents the age of the patients. Column 2 gives the total number of patients (173) observed in the first years of life; subsequently the number of patients is reduced by subtraction of the cases that were no longer under observation. Thus the figures indicate how many patients under observation have passed their respective age-classes.

In column 3 the individual figures tell us how many of the patients (in column 2) have been found to be deaf in the corresponding age-classes. The figures in column 4 give the percentage of deafness calculated for the various age-classes (of 5 years each).

From Table II it is quite evident that the percentage of deafness is increasing greatly with the age of the patients. Even at the age from 30 to 55 years the percentage frequency of deafness is very considerable, and in the age-group of 55-70 years the percentage rises to values representing more than one-half of the patients in that group. For further illustration of this interesting finding, the percentage distribution of deafness after the number of keratitis patients in the various age-classes is presented graphically in Fig. 2. 
TABLE II

\begin{tabular}{|c|c|c|c|c|}
\hline I & II & III & \multicolumn{2}{|c|}{ IV } \\
\hline age & entire material & deaf & $\begin{array}{l}\text { deaf in } \\
\text { entire }\end{array}$ & $\begin{array}{l}\text { rcentage of } \\
\text { material }\end{array}$ \\
\hline $\begin{array}{l}1 \\
2 \\
3 \\
4 \\
5 \\
6 \\
7 \\
8 \\
9 \\
10 \\
11 \\
12 \\
13 \\
14 \\
15 \\
16 \\
17 \\
18 \\
19 \\
20 \\
211 \\
22 \\
23 \\
24 \\
25 \\
26 \\
27 \\
28 \\
29 \\
30 \\
31 \\
32 \\
33 \\
34 \\
35 \\
36 \\
37 \\
38 \\
39 \\
40 \\
41 \\
42 \\
43 \\
44 \\
45 \\
46 \\
47 \\
48 \\
49 \\
50 \\
51 \\
52 \\
53 \\
54 \\
55 \\
56 \\
57 \\
58 \\
59 \\
60 \\
61 \\
62 \\
63 \\
64 \\
65 \\
66 \\
67 \\
68 \\
69 \\
\end{array}$ & $\begin{array}{l}173 \\
173 \\
173 \\
173 \\
173 \\
173 \\
173 \\
173 \\
172 \\
172 \\
172 \\
172 \\
171 \\
168 \\
165 \\
164 \\
160 \\
158 \\
154 \\
148 \\
144 \\
139 \\
132 \\
125 \\
120 \\
109 \\
102 \\
96 \\
89 \\
86 \\
84 \\
79 \\
75 \\
63 \\
57 \\
52 \\
47 \\
44 \\
42 \\
41 \\
40 \\
35 \\
32 \\
29 \\
27 \\
26 \\
24 \\
23 \\
20 \\
20 \\
20 \\
177 \\
15 \\
12 \\
11 \\
10 \\
9 \\
8 \\
7 \\
5 \\
5 \\
5 \\
5 \\
3 \\
2 \\
2 \\
2 \\
2 \\
\end{array}$ & $\begin{array}{r}0 \\
0 \\
0 \\
0 \\
0 \\
0 \\
0 \\
2 \\
4 \\
5 \\
5 \\
5 \\
5 \\
8 \\
9 \\
9 \\
10 \\
10 \\
11 \\
12 \\
12 \\
12 \\
11 \\
11 \\
11 \\
11 \\
12 \\
12 \\
12 \\
12 \\
14 \\
13 \\
13 \\
12 \\
11 \\
9 \\
8 \\
9 \\
9 \\
10 \\
9 \\
9 \\
10 \\
9 \\
8 \\
7 \\
6 \\
7 \\
6 \\
6 \\
7 \\
6 \\
5 \\
5 \\
5 \\
5 \\
6 \\
5 \\
4 \\
3 \\
33 \\
3 \\
33 \\
2 \\
1 \\
1 \\
1 \\
1 \\
1 \\
\end{array}$ & $\begin{array}{c}0 \% \\
0 \\
0 \\
0 \\
0 \\
0 \\
0 \\
0 \\
1,2 \\
2,3 \\
2,9 \\
2,9 \\
2,9 \\
2,9 \\
4,8 \\
5,4 \\
5,4 \\
6,0 \\
6,0 \\
7,1 \\
8,1 \\
8,3 \\
8,5 \\
8,3 \\
8,8 \\
9,1 \\
10,0 \\
11,8 \\
12,5 \\
13,5 \\
13,9 \\
16,7 \\
16,5 \\
17,3 \\
19,0 \\
19,3 \\
17,3 \\
17,0 \\
20,5 \\
21,4 \\
24,4 \\
22,5 \\
25,7 \\
31,2 \\
31,0 \\
29,6 \\
26,9 \\
25,0 \\
30,4 \\
30,0 \\
30,0 \\
35,0 \\
35,0 \\
33,3 \\
41,6 \\
45,5 \\
50,0 \\
66,6 \\
62,0 \\
57,1 \\
60,0 \\
60,0 \\
60,0 \\
60,0 \\
66,6 \\
50,0 \\
50,0 \\
50,0 \\
100 \\
100\end{array}$ & $\begin{array}{l}0 \% \\
1,3 \%\end{array}$ \\
\hline
\end{tabular}


Fig. 2

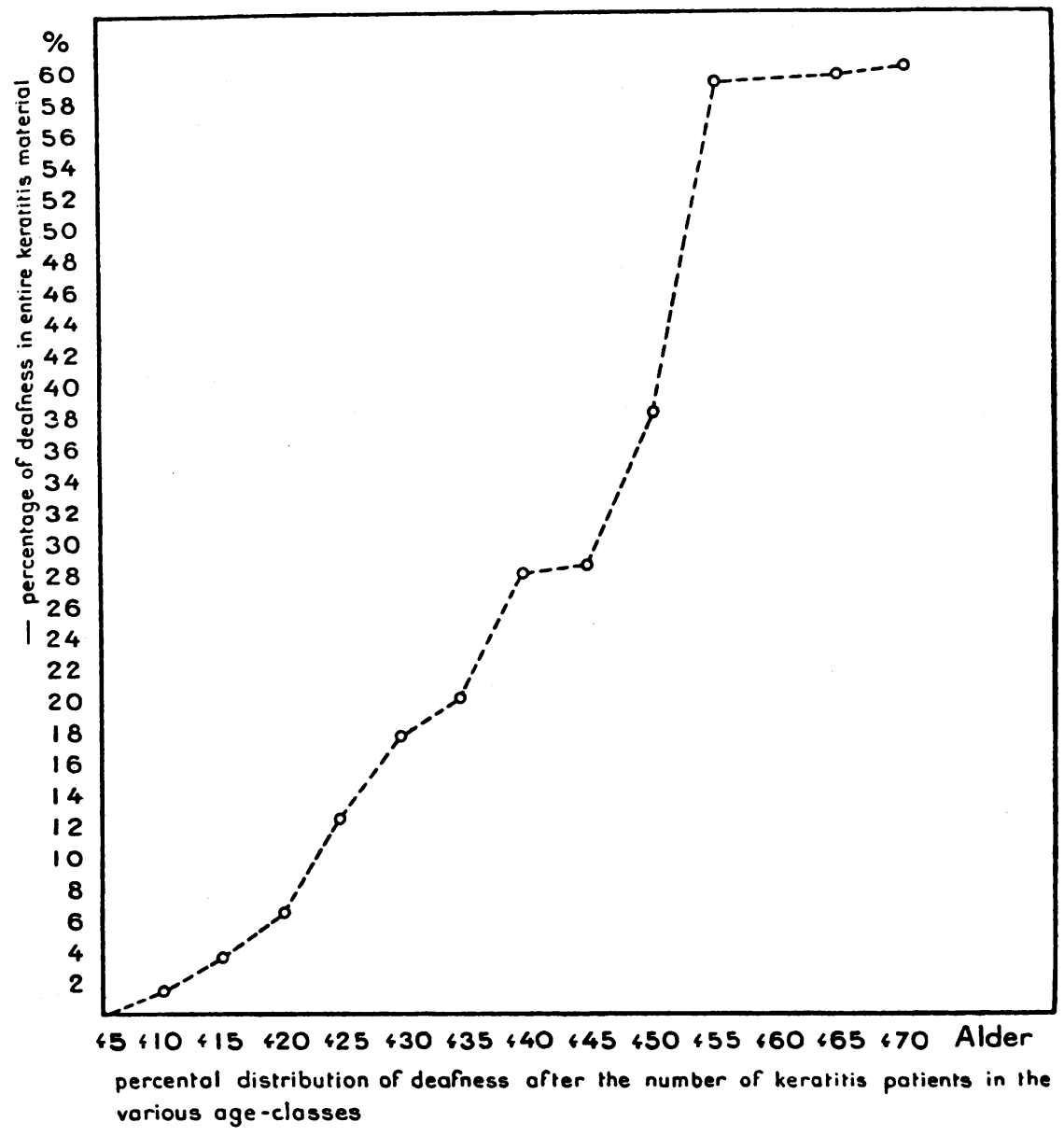

In my material every instance of deafness develops subsequently to the manifestation of keratitis. The interval between keratitis and deafness varied from 1 to 31 years, and it was found to increase with the age of the patient at the manifestation of keratitis. These findings are presented graphically in Fig. 3.

Deafness appeared preferably in those patients in whom the keratitis had taken a more malignant course, and in whom there appeared also other syphilitic symptoms.

As far as nervous complications are concerned, they too brought about a severe degree of disablement in those cases where they were disabling at all. It is to be mentioned at the same time, however, that nervous complications were present in 10 additional 
patients in whom they had not left any disablement that could be demonstrated at the re-examination.

In contrast with the deafness and nervous complications, the impairment of vision has brought about the most varying degrees of disablement-from the very mildest ( 5 per cent.) to the most severe (100 per cent.). An impression of the practical importance of the disablement due to impairment of vision may be obtained through an account of the visual acuity in the better eye. In this respect there is a considerable divergence between the accounts I have been able to find in the literature and my findings. In

Fig. 3

- All reexomined patients with deofness

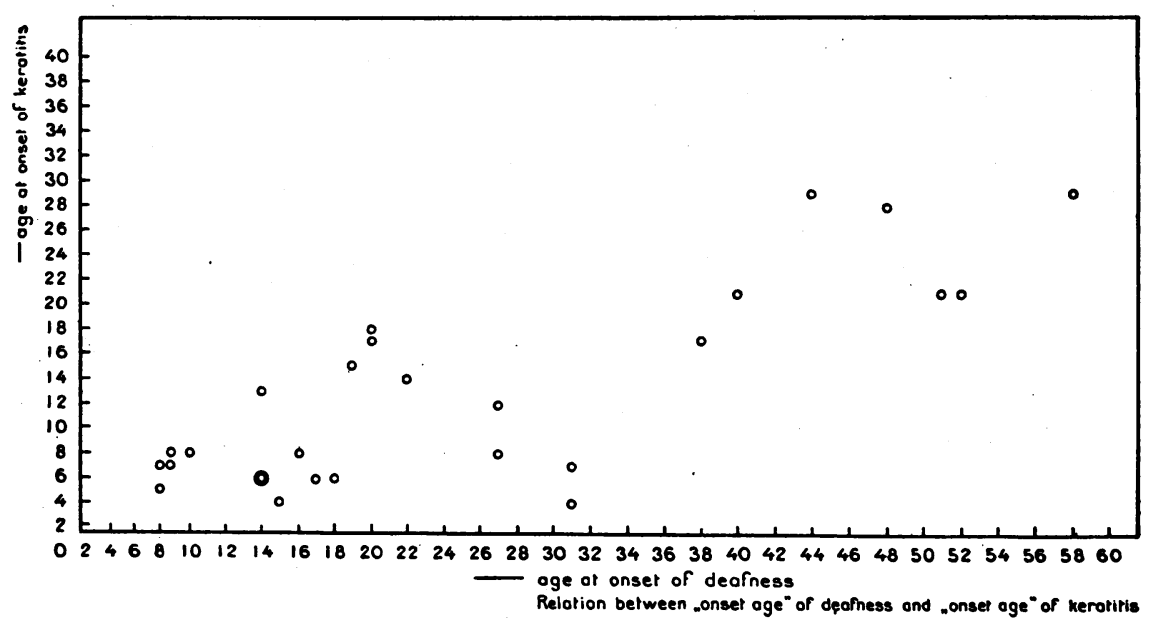

my material only about 5 per cent. of the patients showed an acuity of vision amounting to $6 / 24$ or less, while, for instance, Seefelder ${ }^{6}$ found 49 per cent. with a visual acuity of $<6 / 36$.

Even though this difference is due in part to the fact that my material, on an average, has shown a slight degree of disablement -owing perhaps to the long observation period-it is largely and decisively due to the fact that my account covers also the normal eyes in patients with unilateral keratitis. Here, I may add that unilateral keratitis was found in $\mathbf{1 7}$ per cent. of my patient materiai.

As to the disablement, it was found that on comparison of the length of the observation period with the percentage of disablement, the disablement was increasing markedly with the length of the observation period. In this investigation I have had to rule out a part of my material-namely, those patients who might be regarded as selected as far as disablement is concerned, as some of them had sought medical advice of their own accord and 
others were hospitalized when they turned up for the re-examination. This leaves 122 patients distributed in such a way that, working with groups of 5-year observation periods, the percentage of disablement after an observation period of $0-5$ years was 0 per cent. ( 2 patients); $6-10$ years : 5.5 per cent. (20 patients); $11-15$ years : $9 \cdot 7$ per cent. ( 22 patients); $16-20$ years : $12 \cdot 2$ per cent. ( 20 patients); 21-25 years : 25.5 per cent. (24 patients); $26-30$ years :

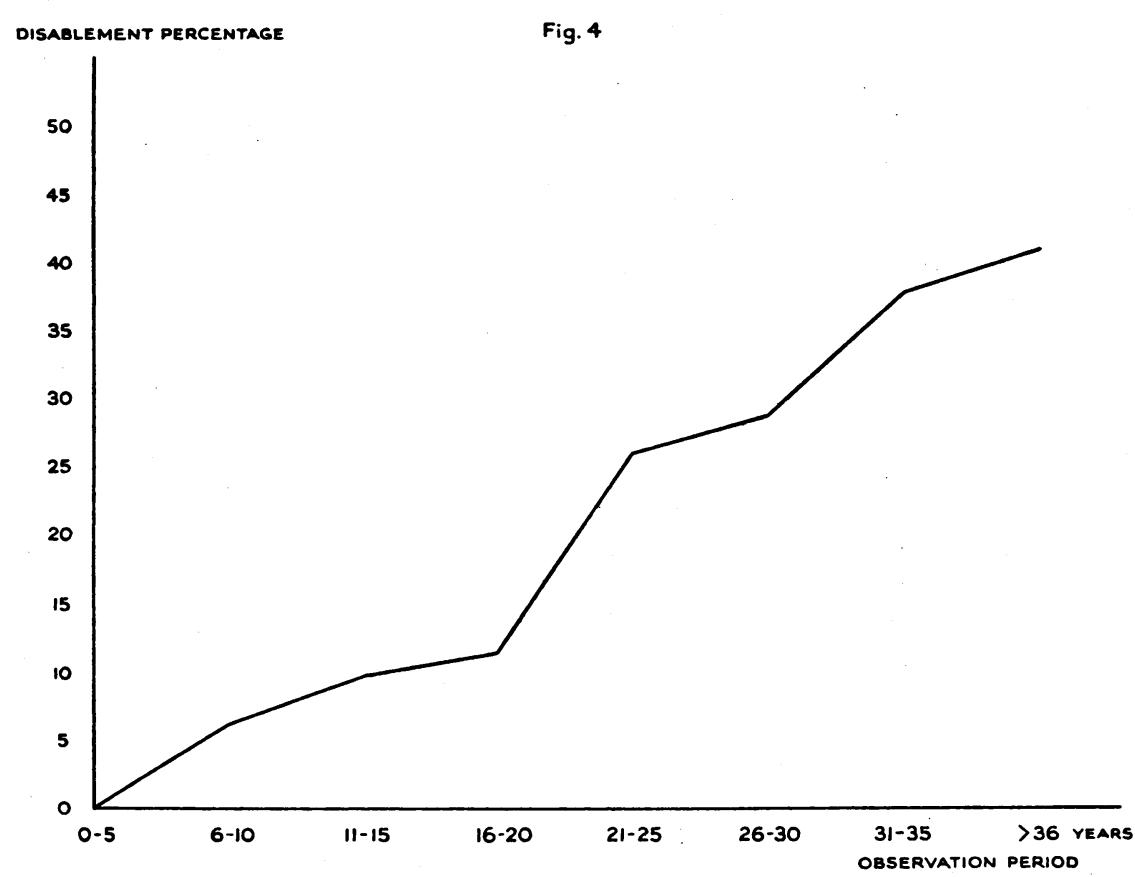

28 per cent. (15 patients); $31-35$ years : 37.5 per cent. (10 patients); over 36 years: 40.5 per cent. (9 patients). These findings are presented graphically in Fig. 4.

Among these 122 patients 40 had not previously received any antisyphilitic treatment. Naturally most of these untreated patients belonged to the older age-groups; and they all had an observation period of more than 21 years, distributed as follows :

$$
\text { years patients }
$$

Observation period of $21-25: 26 \cdot 7$ per cent. disablement in 12

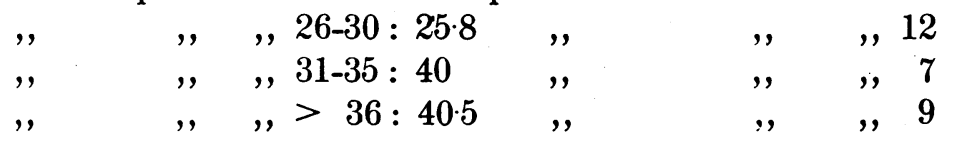


Here, too, we find that a high disablement percentage corresponds to a long observation period. It does not seem possible from a comparison of the disablement percentage in treated and untreated patients to arrive at any sure conclusion as to the influence of treatment upon the degree of disablement. The rise of the disablement percentage with the observation period in my material is due to the development of cataract, cyclitis, choroiditis, and glaucoma, as far as the eyes are concerned, and to deafness and nervous complications, whereas heart disease plays a strikingly minor rôle.

If we try among these 122 patients to appraise the respective rôles played by the impairment of vision, the deafness and the nervous complications as causes of disablement, we arrive at the following average degrees of disablement calculated on the basis of the total material (comprising non-disabled as well as disabled) : impairment of vision : 13.1 per cent.; deafness : 6.5 per cent.; and nervous complications : 0.8 per cent. Among the 49 patients, selected with a view to disablement because they sought medical advice of their own accord and were hospitalized at the reexamination, the corresponding figures were: impairment of vision : 14.7 per cent.; deafness : 8.1 per cent.; nervous complications : 4 per cent.; and heart disease : 2 per cent.

As to the social conditions of these patients, the required information has been difficult to obtain. In the literature, one finds a good many reports on this subject, but often they are rather divergent. Hochsinger ${ }^{7}$ has reported a serial investigation covering 134 syphilitic families in which he found 253 still-born children, 263 living children with congenital syphilis, and only 53 healthy children.

Boas and Roenne ${ }^{8}$ examined 33 families and found 37 still-births or abortions, 47 children with congenital syphilis, 27 normal children, and 21 children on whom no accurate examination had been performed.

In my material 120 families had altogether 469 children, 200 of whom were suffering from congenital syphilis. The greatest number of children with congenital syphilis in one family was 7 . I was not able to obtain reliable information about the number of abortions and still-births in these families.

As a matter of course, naturally, either the mothers or both parents of the interstitial keratitis patients must have had syphilis. For an estimation of the milieu in which the keratitics grew up it would be of particular interest to obtain information about the extent and degree of syphilitic symptoms noticed in the parents of these patients. Several difficulties were encountered however, in trying to obtain this information.

As mentioned already, a great many of these patients did not 
know that their eye lesion was due to congenital syphilis. In other cases the syphilis in the parents had taken a latent course or merely given symptoms that could not be attributed with certainty to the presence of syphilis. Some of the patients have never known their parents; in other cases the parents had died, often many years before this investigation, and frequently the cause of death was not fully established. In my material, 36 out of 110 patients were able to state that both parents or the mother had been syphilitics.

Turning to the subsequent records of my patients, it is found that out of the 173 patients 98 were married (i.e. 57 per cent.). Their average age was 32 years. I have not been able to find out whether matrimony among normal persons at the age of 32 exceeds 57 per cent.

As to the number of children of the 98 married patients, 30 had no children; the remaining 68 families had a total of 142 children. Of these 142 children 7 died from unknown causes in infancy, 2 died at the age of 2 years, 3 had attacks of epileptiform convulsions, and 4 were delicate. Abortion and still-birth were said to have happened in 4 cases.

In 7 cases the Wassermann test was applied to the children, who all gave a negative reaction.

Thus these 98 married keratitic patients had only 142 children altogether-something that agrees very well with the statement made by Igersheimer, ${ }^{4}$ that women who have had interstitial keratitis often are sterile. In the account reported by SidlerHuguenin $^{9}$ it was found that 28 per cent. of such marriages were childless, and that 36 such marriages only resulted in 65 children altogether.

The above, however, has not been confirmed by other investigators. Thus, Treacher Collins ${ }^{10}$ found a normal number of children (4) in families where the mothers gave a past history of interstitial keratitis. Nor did Husler and Wisskoff ${ }^{11}$. find any evidence in their material of patients with past interstitial keratitis of reduction in the capacity for reproduction. On the other hand, Treacher Collins ${ }^{10}$ found that a strikingly large number of these children (26 out of 60 ) died in their first years of life. As pointed out above, my findings point in the same direction.

As to signs of congenital syphilis in children born by mothers with a past history of interstitial keratitis, they might be expected a priori to be rare, as the congenital syphilis of the mother has already reached a late stage at the time the child is born. This view is confirmed on investigation into this particular point: Igersheimer ${ }^{4}$ obtained a negative Wassermann reaction in all the 12 children of past-keratitic mothers he examined, and SidlerHuguenin ${ }^{9}$ obtained a negative Wassermann reaction in 44 out of 45 children examined. 
Concerning the occurrence of syphilis in three generations the reader is referred to two papers by Haldimann ${ }^{12}$ who in 1936 and 1937 reviewed the literature dealing with this question and found altogether 13 cases of patients with eye symptoms suggestive of the presence of syphilis through three generations. Also Bergmeister ${ }^{13}$ and Manchot ${ }^{14}$ have reported some cases of that kind. My material includes no sure case of this kind.

In conclusion I shall merely mention that from the patient's occupations I have tried to gain an impression as to whether the disease may conceivably bring about a reduction in their social standing.

In a group of 51 patients who were investigated, especially with a view to this particular feature, it was found that 38 occupied the same social state as that of their parents, while 7 had advanced socially and 6 had gone down. Practically all the parents belonged to the working and trade classes, and the same applies to the re-examined patients, so that it seems safe to say that the disease has not occasioned any particular social reduction.

\section{REFERENCES}

1. DalsgaARD-Nielsen, Esther.-Keratitis farenchymatosa luica og dens Fclgetilstande særlig belyst ved sene Efterundersoegelser. Dissertation; 1938. Levin \& Munksgaard, Copenhagen.

2. Secher, KNud.-Medicinske Tal, 1934. Levin \& Munksgaard, Copenhagen.

3. Carvill, Maud, and Derby, George S.-Trans. Sect. on Ophthal. Amer. Med. Assoc., 1925 ; ref. Zentralbl.f. d. ges. Ophthal., Vol. XVI, p. 256, 1925.

4. Igersheimer.- Syphilis und Auge. Julius Springer, Berlin, 1928, 2nd Ed.

5. DalsgaAd-Nielsen, Esther.-Acta Ophthal., Vol. XVI, 1938.

6. SeEFELder.-Arch. f. Augenheilk., Vol. CVII, p. 16, 1933.

7. Hochsinge R, C.-Münch. med. Wochenschr., Vol. XXI, p. 1156, 1910.

8. BoAs and Roenne.-Klin. Monatsbl. f. Augenheilk., Vol. LII, p. 219, 1914.

9. Sidler-Huguenin.-Schweiz. med. Wochenschr., Vol. LI, p. 49, 1921.

10. Treacher Collins. - Ophthal. Hosp. Reps, ref. Zentralbl. f. d. ges. Ophthal., Vol. XV, p. 206, 1925.

11. HUSLER and WISSKOFF.-Klin. Wochenschr., Vol. XIV, p. 269, 1926.

12. Haldimann, CaRL.-Zeitschr.f. Augenheilk., October, 1936, and Vol. XCI, 1937.

13. Bergmeister, R.-Zeitschr. f. Augenheilk., Vol. LXII, p. 100, 1927.

14. Manchot. Deutsch. med. Wochenschr., Vol. LII, p. 1534, 1926. 